\title{
Individual and Combined Toxic Effects of Herbicides on Growth Parameters and Fecundity of Eisenia fetida
}

\author{
Anshu*, Dharambir Singh, Mahima and Shweta \\ Department of Zoology, Chaudhary Charan Singh Haryana Agricultural University, \\ Hisar, Haryana 125004, India \\ *Corresponding author
}

\section{A B S T R A C T}

\section{Keywords}

Eisenia fetida,

Fecundity,

Glyphosate,

Herbicides and

Pendimethalin

Article Info

Accepted:

14 November 2020

Available Online:

10 December 2020
The present study investigated the effect of herbicides on survival, growth parameters and fecundity of E. fetida for 90 days. Different doses of herbicides viz. Pendimethalin and Glyphosate were used individually and in combinations. Minimum number of survived adult earthworm and least number of cocoons counted were $17.6 \pm 0.33 \& 19.6 \pm 0.66$ respectively in tubs where worms were treated with Pendimethalin+Glyphosate @ $1.50+2.50 \mu 1 / \mathrm{kg}$ of substrate. Similarly minimum body weight $(0.40 \pm 0.06$ gram $)$ and length $(6.56 \pm 0.34 \mathrm{~cm})$ gain was also in same treatment. Individually Pendimethalin was more lethal when compared with Glyphosate.

\section{Introduction}

Earthworms contribute a lot to the soil biodiversity; they are the basic driver of abiotic and biotic soil properties. Their feeding, burrowing and casting activities influences the structure of soil, regulation of water, bioremediation of toxins, organic matter distribution and soil structure. They can modify soil porosity, water infiltration, soil aeration and fertility. So earthworms are also known as ecosystem engineers in the terrestrial soils due to their contribution in pedogenesis.
Indiscriminate use of pesticides, herbicides, inorganic fertilizers and other metal mixtures at large scale to enhance agriculture production have had negative effects on soil fauna, especially earthworms and they are being killed as non-targeted organisms. Non judicious use of agrochemicals may induce damage at genetic level, disruption in enzyme activities, low survival rate, reduced reproduction and growth rate etc which ultimately results in decreased total earthworm biomass. 
Earthworms are the best bio-indicator of relative health of ecosystem as compared to other terrestrial invertebrates. These worms are also used in monitoring soil pollution in the field; changes in abundance, biomass, or species richness of natural populations due to stress conditions have been common ecological endpoints to identify point-sources of pollution. One of the earthworm species, $E$. fetida minimizes the pollution danger caused by organic wastes degradation and internationally used as reference animal for toxicity studies. Earthworm metabolizes the parent compound of herbicide in their gut, by transporting the herbicides at the depth or by absorbing herbicide residues in their tissues they influence the persistence of herbicides in soil. Humans extensively use Glyphosatebased herbicides and Pendimethalin in agriculture, forestry, horticulture and urban settings. Earthworms as soil dwellers are easy and likely non-target organisms for Glyphosate and Pendimethalin.

So taken into consideration of all the above mentioned concerns, present investigation was planned to study the effect of herbicides on various growth parameters of E. fetida.

\section{Materials and Methods}

\section{Collection of the test animal:}

The culture of earthworm species E. fetida was perpetuated to use the third generation of earthworms to avoid the pre-exposure or residual effects of agrochemicals at vermicomposting unit of Department of Zoology, CCSHAU, Hisar. Mature and completely clitellated earthworms were used for experimentation to evaluate the effect of herbicides on growth parameters and reproductive potential.

\section{Collection of substrate}

The cow dung, used as substrate was obtained from Biogas Plant of Department of Microbiology, CCS HAU, Hisar. Prior to study, the deleterious effect of harmful gases and increase in temperature of cow dung during vermicomposting was ruled out by pre decomposing it for 15 days.

\section{Procurement of herbicides}

Most commonly used herbicides, Glyphosate and Pendimethalin were procured from Kisan Seva Shop Hisar.

\section{Effect of herbicides on various growth parameters of $E$. fetida}

Twenty healthy and fully clitellated earthworm were selected, washed, weighed and released in each tub of $90 \mathrm{~L}$ capacity. Thereafter, earthworms were checked to ensure that all worms had burrowed into the substrate present in tubs. Two chemicals Glyphosate and Pendimethalin of different concentration (Table 1) were sprayed in each tub except control. Triplicates of each treatment were maintained for duration of 90 days.

Mortality and growth parameters were measured after every 30 days by counting, weighing and measuring the surviving worms in each tub. The worms were considered alive which were able to respond to a mechanical stimulus. Cocoons were also collected by sorting from the substrate after every 30 days and total numbers of cocoons were counted per replicate.

\section{Results and Discussion}

\section{Survivability of earthworms}

The exposure of earthworms to different concentrations of herbicides significantly reduced the number of adult earthworm, further the number of survived worms decreased with increase in concentration of 
herbicides. The effect of herbicicdes i.e. Glyphosate and Pendimethalin was observed on the survivability of earthworm and graphically shown in Fig 1. The study revealed after 90 day of experimentation that minimum number of adult earthworm (17.6 \pm 0.33$)$ survived in substrate treated with combined dose of Pendimethalin+Glyphosate @ $1.50+2.50 \mu \mathrm{l} / \mathrm{kg}$ of substrate, whereas minimum numbers of survived worms was $23 \pm 0.57$ and $20 \pm 1.15$ in tubs treated with Glyphosate and Pendimethalin @ 5.00 $\mu 1 / \mathrm{kg}$ and $3.00 \mu 1 / \mathrm{kg}$ respectively. Individually Pendimethalin was more toxic than Glyphosate (Zhou et al., 2007; Zhou et al., 2011; Santos et al., 2012) reported similar results due to Chlorpyrifos toxicity and its negative effect on the growth rate and reproductive potential of earthworm E. fetida and E.andrei. Booth et al., 2000 observed significant negative effects of Chlorpyrifos on Aporrectodea caliginosa .Correia et al., (2010) conducted laboratory tests on E. fetida by exposing them tovarious concentrations of Glyphosate and 2,4-D and compared the effects. The growth, survival, and reproduction rates of earthworm for different exposure times and found that Glyphosate and 2, 4-D had detrimental effects on the development and reproduction of E. fetida, these results are in accordance with our results. Hattab et al., (2015) also studied the effect of 2,4-D on $E$. andre $i$ and observed that at concentration of 7 and $14 \mu \mathrm{l} / \mathrm{kg}$ after exposure for 7 and 14 days significantly reduced the body weight of E.andrei. These types of observations strongly favour results of present investigation that chemicals have negative effect on growth and reproduction of earthworms.

Previous studies showed that effect of 2, 4$\mathrm{DE}$ on growth of earthworms is more as compared to Chlorpyrifos for initial two lower concentrations but their combined effect was found more severe as compared to their individual effect as their combined concentrations show gradual fall in growth, rate of biomass with increase in level of concentration. Past observations shows similarity with our study in which combined doses of Pendimethalin and Glyphosate shows more toxicity in comparison to Pendimethalin and Glyphosate individually.

Wang et al., (2016) investigated the individual and combined toxic effects of three insecticides chlorpyrifos, lambda-cyhalothrin and imidacloprid and herbicide atrazine on $E$. fetida. Their results showed that imidacloprid had highest toxicity to E. fetida followed by lambda-cyhalothrin and atrazine though chlorpyrifos was found least toxic to worms. The binary mixture of atrazine-lambdacyhalothrin and ternary mixture of atrazinechlorpyrifos-lambda-cyhalothrin showed significant synergistic negative effect on the earthworms.

Khandelwal (2017) also observed detrimental effects on growth and fecundity of earthworms due to combined effect of Chlorpyrifos and 2,4-DE as compared to individual application while antagonistic effects were observed in case of combined effect of Triazophos and Pendimethalin.

\section{Number of cocoons}

The observations were taken from the initial day of exposure of worms to herbicides, up to $90^{\text {th }}$ day of study and are presented in Fig. 2. After $90^{\text {th }}$ day, minimum number of earthworm cocoons $(19.6 \pm 0.66)$ were found in tubs treated with Pendimethalin+ Glyphosate@1.50+ 2.50) $\mu 1 / \mathrm{kg}$ of substrate whereas in case of Glyphosate $(5.00 \mu 1 / \mathrm{kg})$ and Pendimethalin $(3.00 \mu \mathrm{l} / \mathrm{kg})$ individually, the number of earthworm cocoon were $35 \pm 0.57$ and $27.3 \pm 0.66$ respectively.

Sorour and Larink in 2001 checked the 
toxicity of various concentrations of fungicide benomyl on the male reproductive system of E. fetida for one week and their results demonstrated that fungicides has negative effect on spermatozoa of E. fetida and cause nuclear distortion, incomplete formation of acrosome and microtubules disruption. Similarly toxicity of Glyphosate on soil fauna and population dynamics was assessed by treating $E$. fetida with its different concentrations of Glyphosate (Santadino et al., 2014). Their results suggest that Glyphosate had negative effect on growth parameters and fecundity of E. fetida. Our results match with the findings of Zhouet al., (2011) who studied the impact of pyrethroid (cypermethrin) and an organophosphate insecticide (chlorpyrifos) individually and their combination. Their results for combination of cypermethrin and chlorpyrifos were more detrimental and significantly reduced the growth and reproduction rate of E. fetida.

Gómez et al., in 2019 studied the effect of $\mathrm{ZnO}$ nanoparticles and organophosphate insecticide chlorpyrifos and observed the significant reduction in fertility and reproductive potential of E.andrei at different concentrations. They also observed that the binary mixtures showed a synergism (a stronger effect than expected from single exposures) on earthworm reproduction.

\section{Body weight of earthworm}

The Body weight gain of earthworms exposed to herbicides and minimum weight gain $(0.373 \pm 0.01$ gram) was found in adult earthworm treated with combined dose of Pendimethalin+Glyphosate @ 1.50+2.50 $\mu 1 / \mathrm{kg}$ of substrate. In case of Glyphosate $(5.00 \mu 1 / \mathrm{kg})$ and Pendimethalin $(3.00 \mu \mathrm{l} / \mathrm{kg})$ individually, gain in weight of adult earthworm was $0.50 \pm .03$ gram and $0.486 \pm 0.05$ gram respectively.
The finding reveals the fact that prolonged exposure of earthworms to agrochemicals may have interfered with the metabolism of worms and thus have resulted in a reduction in body weight. Our results are similar to the observations recorded by Gobi \& Gunasekaran (2010); they checked the toxicity of different concentrations of herbicide butachlor $(0.2575 \mathrm{ml}, 0.5150 \mathrm{ml}$, and $2.5750 \mathrm{ml}$ ) on the biomass and cocoon production potentiality of earthworms for over the period of 60 days. They observed that as the concentration of herbicides was increased biomass and cocoon production reduced significantly. Yasmin and D'Souza (2007) also studied the effects of three different pesticides (carbendazim, dimethoate, and Glyphosate) and Mixture of all the three chemicals on growth and reproduction of the earthworm species, E. fetida. Their results showed that the pesticide treatment had a marked negative impact on the growth and reproductive ability of earthworms. Carbendazim and dimethoate were found to cause more harm to the selected earthworm species than Glyphosate. Carbendazim, Dimethoate, and the mixture of the three pesticides had a significant negative impact on the weights and fecundity (Fig. 3).

Identical studies on growth, reproduction, and avoidance behavior of an earthworm, E. fetida were carried by (Farrukh, 2011) by using dichlorovos and dose-dependent decrease in the weight of earthworms at all concentrations of the pesticide was recorded. The reproductive potential and avoidance behavior are susceptible parameters and were also found significantly affected by the different concentrations of dichlorovos. Their findings proved that growth, reproduction and avoidance behavior can be assessed as major indicators to check the sub lethal effects of agrochemicals on soil fauna like earthworms. Species like E. fetida and Octolasion tyrtaeum were exposed to five different concentrations 
of Glyphosate. Among these two species $O$. tyrtaeum was found more susceptible to herbicide and highest mortality was observed at the higher concentration of Glyphosate. Significant loss in weight was observed in $E$. fetida at the highest concentration.

Significant reduction in biomass and cocoon production was also observed in $P$. corethrurus by García-Pérez et al., 2020) when they exposed earthworms to recommended doses of Glyphosate-based herbicides (GBHs) and recorded their interactive effect on worms. Number of cocoon produced and biomass of earthworms was regularly measured after every 12th day for 168 days. Similar to results of present study, their observations revealed that cumulative doses of herbicides were more detrimental for $P$. corethrurus

Table.1 Three treatments were given to the earthworm along with control

\begin{tabular}{|c|l|l|}
\hline Sr. No. & Treatment & Concentration (micro liter/kg substrate) \\
\hline $\mathbf{1 .}$ & Control & 0.00 \\
\hline $\mathbf{2 .}$ & Pendimethalin & $1.50,2.25,3.00$ \\
\hline $\mathbf{3 .}$ & Glyphosate & $2.50,3.75,5.00$ \\
\hline $\mathbf{4 .}$ & Pendimethalin+Glyphosate & $0.75+1.25,1.13+1.88,1.50+2.50$ \\
\hline
\end{tabular}
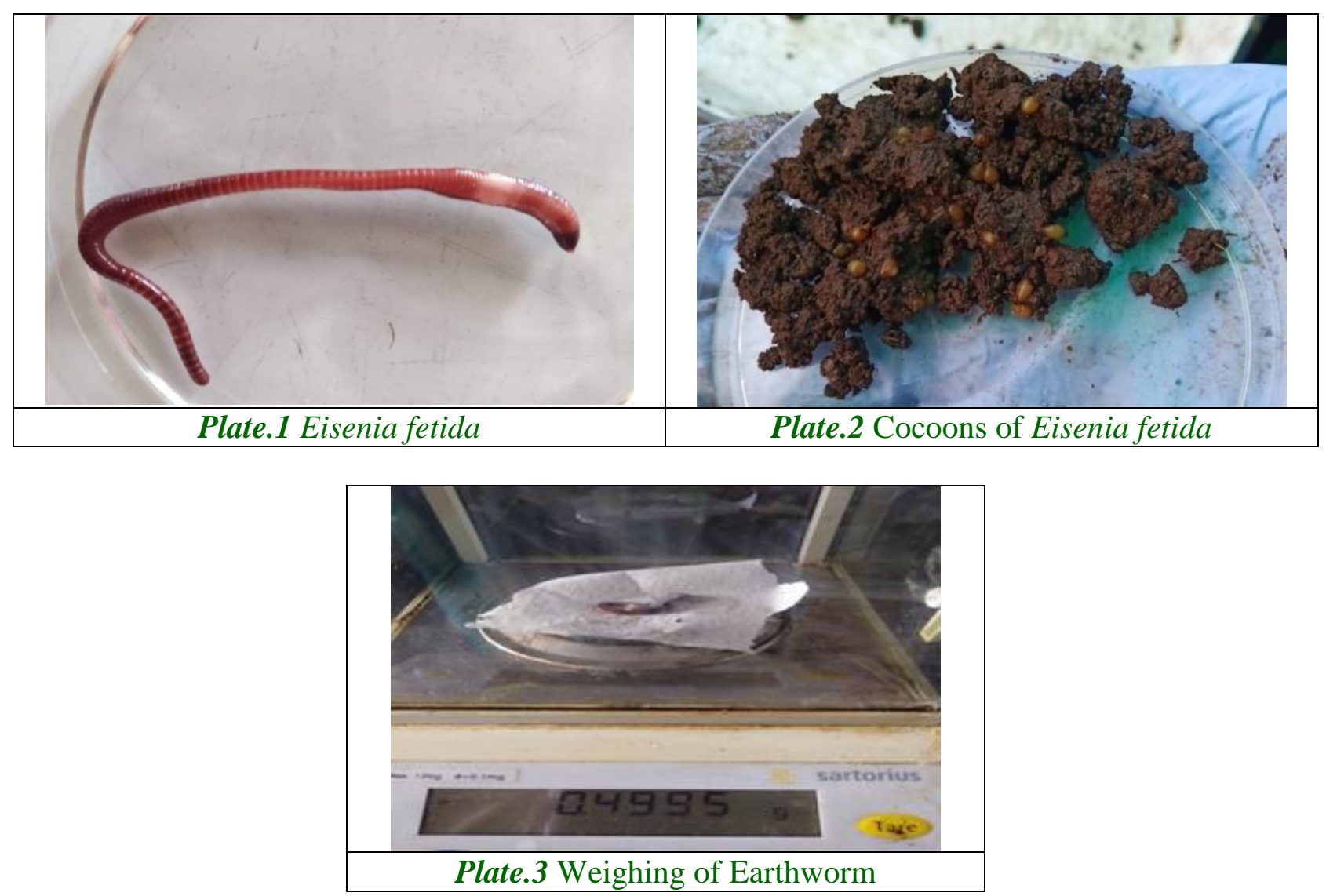


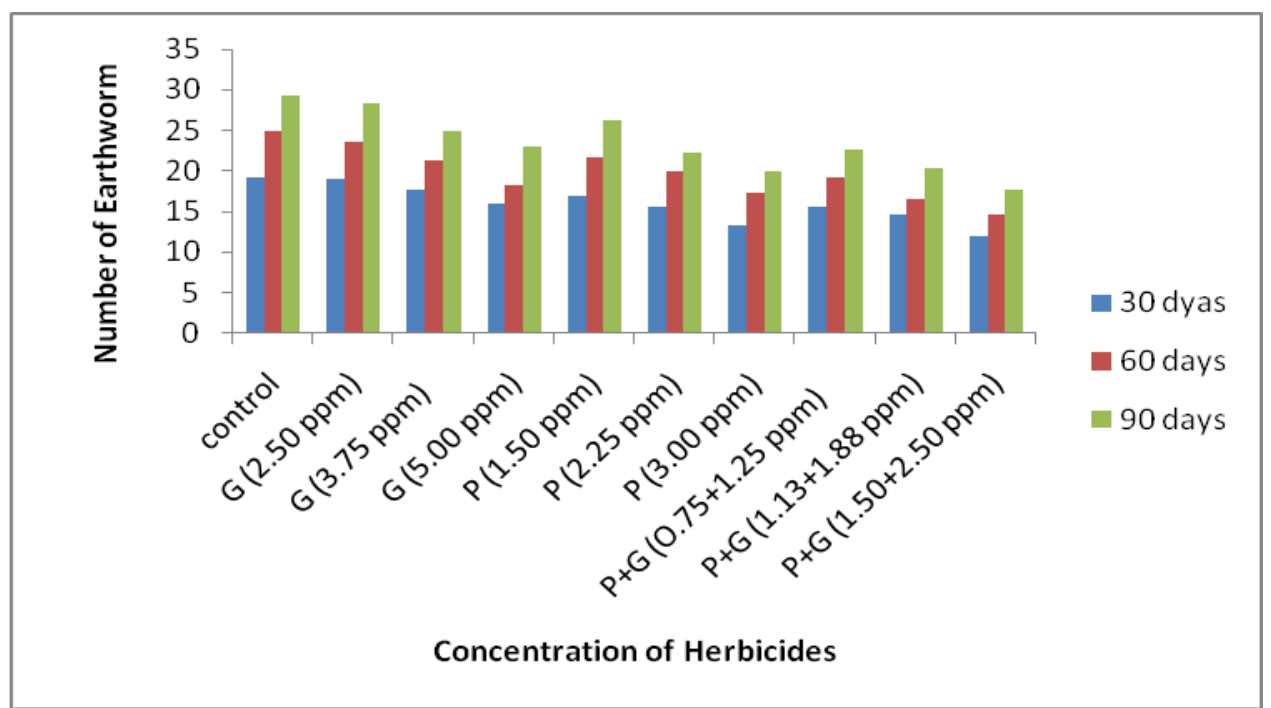

Figure.1 Effect of herbicides on the survivability of adult earthworm, E. fetida

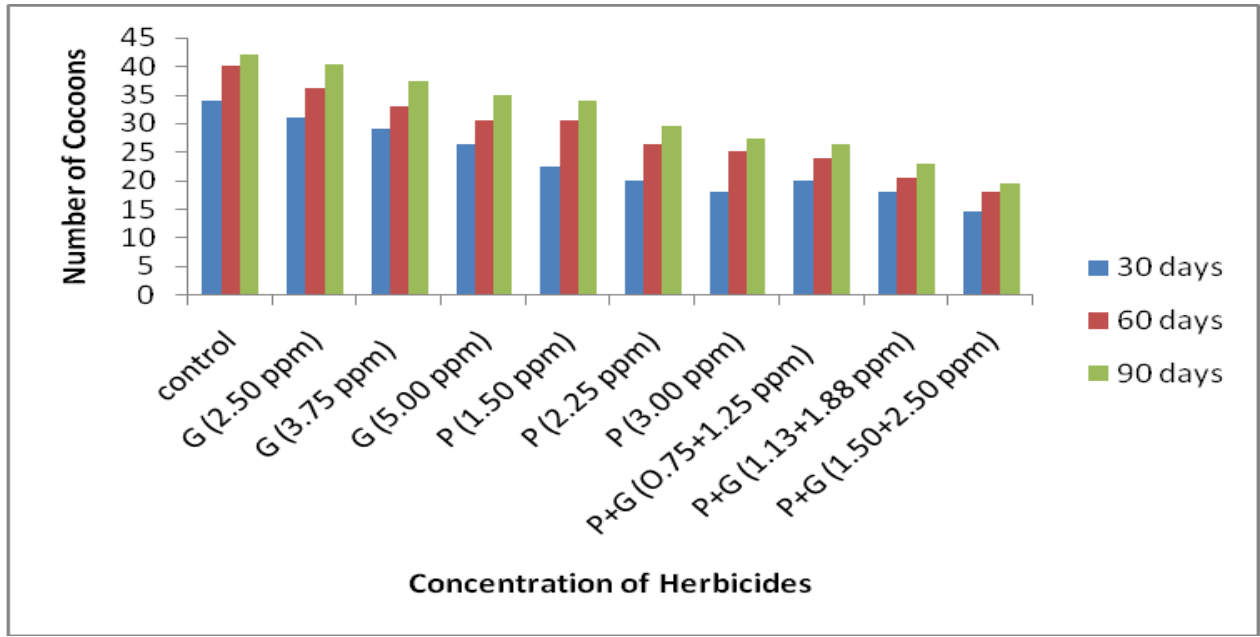

Figure.2 Effect of herbicides on the number of cocoons produced by earthworm, E. fetida

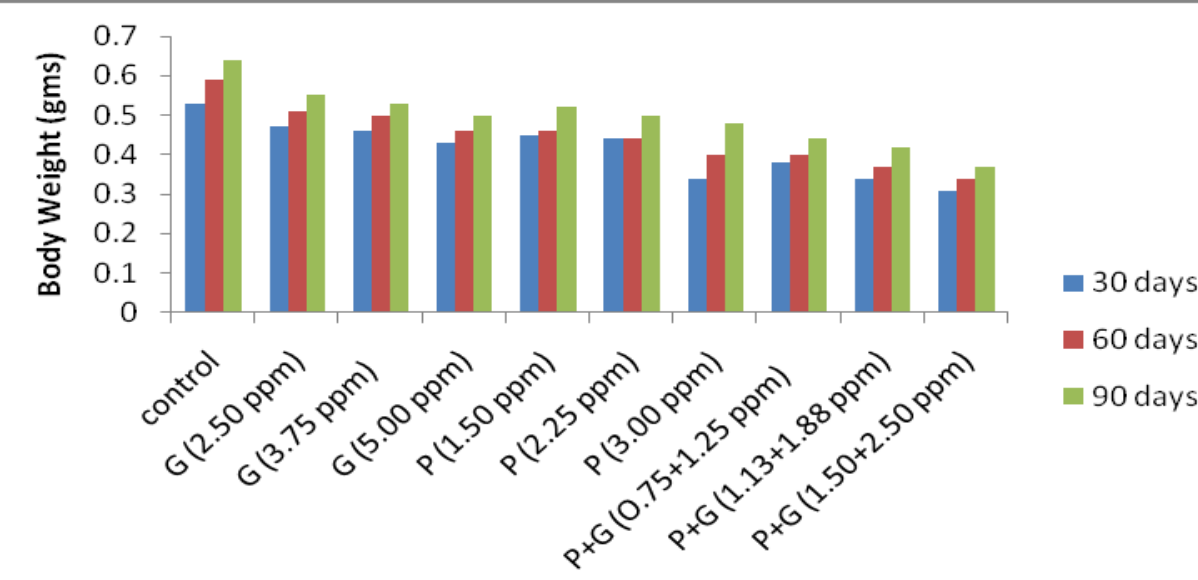

Concentration of Herbicides

Figure.3 Effect of herbicides on the body weight of earthworm, E. fetida 


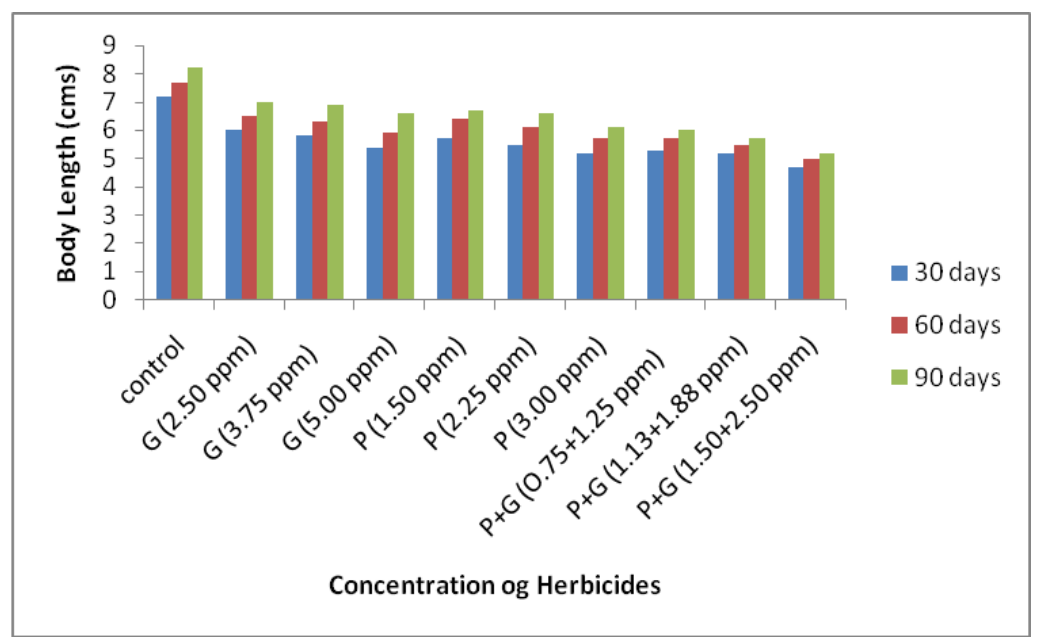

Figure.4 Effect of herbicides on the length of earthworm, E. fetida

\section{Length of earthworm}

Significant changes took place in the length of earthworms after different treatments of herbicides individually and in combination, minimum length $(0.373 \pm 0.01 \mathrm{~cm})$ was recorded after $90^{\text {th }}$ day of treatments in the tubs treated with Pendimethalin+Glyphosate @ $1.50+2.50 \mu 1 / \mathrm{kg}$ of substrate, whereas in Glyphosate $(5.00 \mu \mathrm{l} / \mathrm{kg})$ and Pendimethalin $(3.00) \mu 1 / \mathrm{kg}$ ) individually, body length up to $6.6 \pm 0.05 \mathrm{~cm}$ and $6.16 \pm 0.08 \mathrm{~cm}$ was recorded respectively (Fig. 4).

The exposure of pesticide caused a reduction in body length and this may be mainly due to non-availability of energy, which resulted in the low gain in length in earthworms exposed to chemicals (Jovanaet al., 2014).

Similarly (Chen et al., 2018) also studied the toxic effects of tribenuron-methyl (TBM) and tebuconazole (TEB) on the soil earthworm, $E$. fetida and found that the combination of two pesticides had an adverse effect on earthworms growth in comparison to tribenuron-methyl (TBM) and tebuconazole (TEB) individually and their investigation favours results of present study.

In conclusion, the observations recorded on survivality and growth parameters revealed that both the herbicides under investigation had pernicious effect on survivality, length and weight gain. Minimum number of adult earthworm survived weight and length gain was $(17.6 \pm 0.33), \quad(0.373 \pm 0.01$ gram $)$ and $(0.373 \pm 0.01 \mathrm{~cm})$ respectively in substrate treated with combined doses of Pendimethalin+Glyphosate@ @ 1.50+2.50 $\mu 1 / \mathrm{kg}$ of substrate, whereas individually Pendimethalin @3.00 $\mu 1 / \mathrm{kg}$ and Glyphosate @5.00 $\mu 1 / \mathrm{kg}$ also had toxic effect on survivility, weight and length gain in adult earthworm when compared with control. Combined effects of different doses of Glyphosate +Pendimethalin were most damaging on reproductive potential of $E$. fetida and minimum number of earthworm cocoons (19.6 \pm 0.66$)$ were found in tubs treated with combined doses of Pendimethalin+Glyphosate @1.50+ $2.50 \mu 1 / \mathrm{kg}$. Individually Pendimethalin was more baneful when compared with Glyphosate.

\section{Acknowledgement}

The sincere vote of thanks is offered to the Department of Zoology, Chaudhary Charan Singh Haryana Agricultural University, Hisar for providing the essentialities timely for carrying out the research work 


\section{References}

Booth, L. H., Heppelthwaite, V. J.and O'Halloran, K. (2000). Growth, development and fecundity of the earthworm Aporrectodea caliginosa after exposure to two organophosphates. New Zealand Plant Protection, 53: 221-225.

Chen, J., Saleem, M., Wang, C., Liang, W. and Zhang, Q. (2018). Individual and combined effects of herbicide tribenuron-methyl and fungicide tebuconazole on soil earthworm Eisenia fetida. Scientific reports, 8(1): $1-9$.

Correia, F. V. and Moreira, J. C., (2010). Effects of glyphosate and 2, 4-D on earthworms (Eisenia foetida) in laboratory tests. Bulletin of environmental contamination and toxicology, 85(3): 264-268.

Farrukh, S. (2011). Effects of dichlorovos organophosphate on growth, reproduction, and avoidance behavior of earthworm Eisenia foetida. Iranian Jouranal Of Toxicology 5(14):495501.

García-Gómez, C., Babín, M., García, S., Almendros, P., Pérez, R. A., \& Fernández, M. D. (2019). Joint effects of zinc oxide nanoparticles and chlorpyrifos on the reproduction and cellular stress responses of the earthworm Eisenia andrei. Science of the total environment, 688, 199-207.

García-Pérez., J. A., Alarcón-Gutiérrez, E. and Díaz-Fleischer, F. (2020). Interactive effect of glyphosate-based herbicides and organic soil layer thickness on growth and reproduction of the tropical earthworm Pontoscolex corethrurus (Müller, 1857). Applied Soil Ecology, 155: 103648.

Gobi, M. and Gunasekaran, P. (2010). Effect of butachlor herbicide on earthworm
Eisenia fetida ,its histological perspicuity. Applied and Environmental Soil Science, 2010(4).

Hattab, S., Boughattas, I., Boussetta, H., Viarengo, A., Banni, M., \& Sforzini, S. (2015). Transcriptional expression levels and biochemical markers of oxidative stress in the earthworm Eisenia andrei after exposure to 2, 4dichlorophenoxyacetic acid (2, 4D). Ecotoxicology and Environmental Safety, 122, 76-82.

Jordaan, M. S., Reinecke, S. A. and Reinecke, A. J. (2012). Acute and sublethal effects of sequential exposure to the pesticide azinphos-methyl on juvenile earthworms

(Eisenia andrei).Ecotoxicology, 21(3):649-661.

Khandelwal, A. (2014) A Study on the impact of Pesticides and Herbicides on the Growth and Reproduction of Earthworm in Kota Region.

Khandelwal, A. (2014) A Study on the impact of Pesticides and Herbicides on the Growth and Reproduction of Earthworm in Kota Region.

Santadino, M., Coviella, C. and Momo, F.( 2014). Glyphosate sublethal effects on the population dynamics of the earthworm Eisenia fetida (Savigny, 1826). Water Air Soil Pollution. 225: 2207.

Santos, M. J. G., Ferreira, M. F. L., Cachada, A., Duarte, A. C. and Sousa, J. P. (2012).Pesticide application to agricultural fields: Effects on the reproduction and avoidance behavior of Folsomia candida and Eisenia andrei. Ecotoxicology, 21: 2113-2122

Sorour, J. and Larink, O. (2001). Toxic effects of benomyl on the ultrastructure during spermatogenesis of the earthworm Eisenia fetida. Ecotoxicology and Environmental Safety, 50(3): 180-188.

Wang, Y., An, X., Shen, W., Chen, L., Jiang, 
J., Wang, Q. and Cai, L. (2016). Individual and combined toxic effects of herbicide atrazine and three insecticides on the earthworm, Eisenia fetida. Ecotoxicology, 25(5): 991-999.

Yasmin, S. and Souza, D.D., (2007).Effect of pesticides on the reproductive output of Eisenia fetida. The Bulletin of Environmental Contamination Toxicology, 79: 529-533.

Zhou S, Duan C, Fu H, Chen Y, Wang X. and
$\mathrm{Yu}$ Z. Toxicity assessment for chlorpyrifos-contaminated soil with three different earthworm test methods. Journal of Environmental Sciences (2007). 19: 854-858.

Zhou S, Duan C, Michelle WHG, Yang F, and Wang $X$. Individual and combined toxic effects of cypermethrin and chlorpyrifos on earthworm. Journal of Environmental Sciences. 2011;23(4): 676-68.

\section{How to cite this article:}

Anshu, Dharambir Singh, Mahima and Shweta. 2020. Individual and Combined Toxic Effects of Herbicides on Growth Parameters and Fecundity of Eisenia fetida. Int.J.Curr.Microbiol.App.Sci. 9(12): 1997-2005. doi: https://doi.org/10.20546/ijcmas.2020.912.236 